Provided for non-commercial research and education use. Not for reproduction, distribution or commercial use.

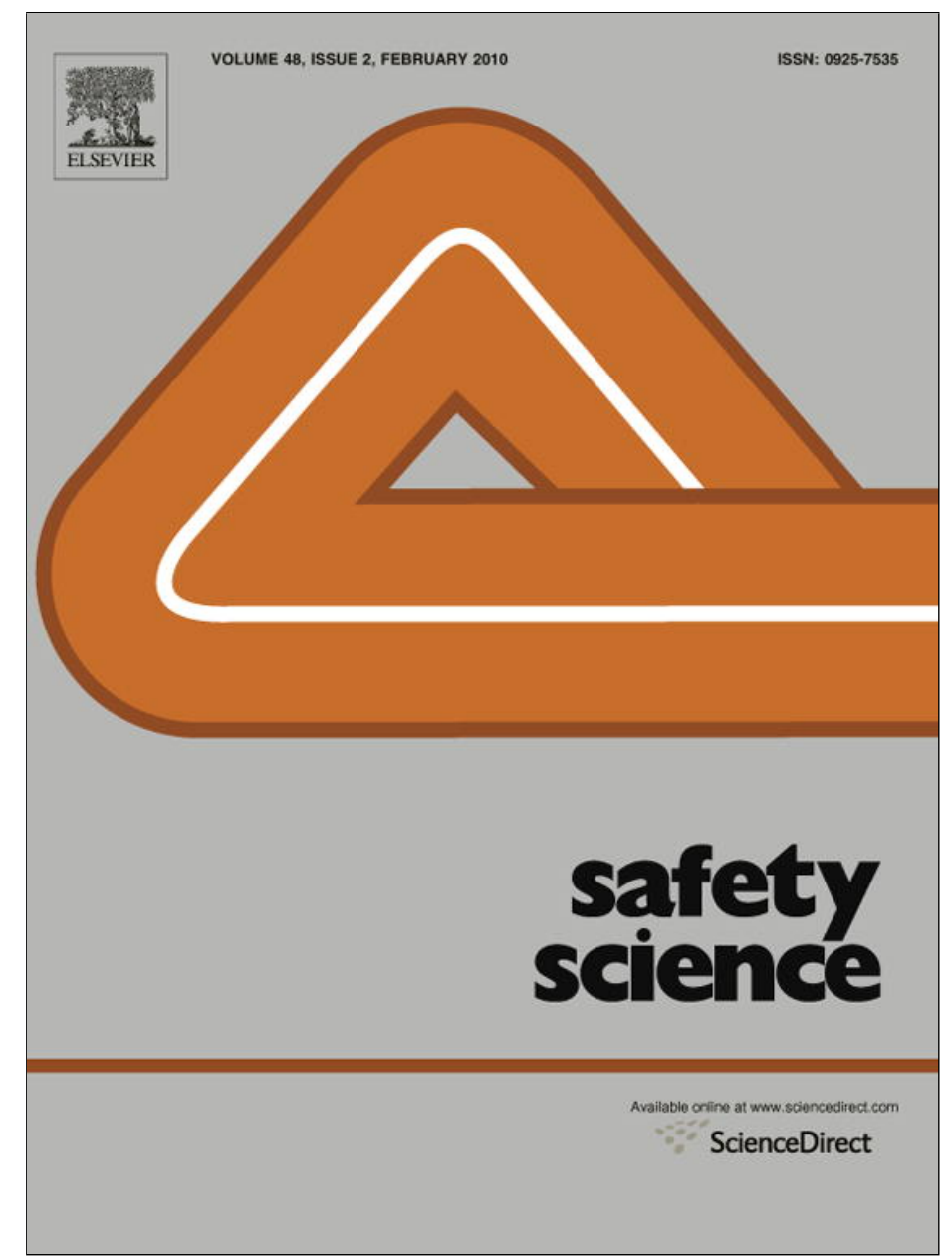

This article appeared in a journal published by Elsevier. The attached copy is furnished to the author for internal non-commercial research and education use, including for instruction at the authors institution and sharing with colleagues.

Other uses, including reproduction and distribution, or selling or licensing copies, or posting to personal, institutional or third party websites are prohibited.

In most cases authors are permitted to post their version of the article (e.g. in Word or Tex form) to their personal website or institutional repository. Authors requiring further information regarding Elsevier's archiving and manuscript policies are encouraged to visit:

http://www.elsevier.com/copyright 


\title{
Analyzing motorists' responses to temporary signage in highway work zones
}

\author{
Yong Bai ${ }^{\mathrm{a}, *}$, Kris Finger ${ }^{\mathrm{b}, 1}$, Yue $\mathrm{Li}^{\mathrm{b}, 1}$ \\ ${ }^{a}$ Department of Civil, Environmental and Architectural Engineering, The University of Kansas, 1530 W. 15th Street, 2135-B Learned Hall, Lawrence, Kansas 66045, USA \\ ${ }^{\mathrm{b}}$ Department of Civil, Environmental and Architectural Engineering, The University of Kansas, 1530 W. 15th Street, 2150 Learned Hall, Lawrence, Kansas 66045, USA
}

\section{A R T I C L E I N F O}

\section{Article history:}

Received 23 January 2009

Received in revised form 13 August 2009

Accepted 17 August 2009

\section{Keywords:}

Crash

Motorist

Safety

Signage

Work zone

\begin{abstract}
A B S T R A C T
For decades, the importance of highway work zone safety has increased considerably with the continual increase in the number of highway work zones present on highways for repairs and expansion. Rural work zones on two-lane highways are particularly hazardous and cause a significant safety concern due to the disruption of regular traffic flow. In this study, researchers determined motorists' responses to warning signs in rural, two-lane highway work zones. The researchers divided vehicles into three classes (passenger car, truck, and semitrailer) and compared the mean change in speed of these classes based on three different sign setups: portable changeable message sign (PCMS) OFF, PCMS ON with the message of Slow Down, Drive Safely, and a temporary traffic sign (W20-1, "Road Work Ahead"). Field experiments were conducted on two two-lane work zones with flagger control. Statistical analyses were performed to determine whether there was a significant interaction between motorists' responses and the sign setups. Data analysis results show that a visible PCMS, either turned on or off, was most effective in reducing truck speeds in rural, two-lane work zones. The temporary traffic sign (W20-1) was more effective in reducing the vehicle speeds of passenger car and semitrailer. Results of this research project will help traffic engineers to better design the two-lane work zone setup and take necessary safety countermeasures to prevent vehicle crashes.
\end{abstract}

(c) 2009 Elsevier Ltd. All rights reserved.

\section{Introduction}

Safety within highway work zones has been an important issue and a major concern of engineers, government agencies, the highway industry, and the public for decades due to the disruption of regular traffic flows. This safety concern has been a focus of both government organizations and researchers alike. Recently, the federal government of the United States has recognized its importance and addressed the issue with the Safe, Accountable, Flexible, Efficient Transportation Equity Act: A Legacy for Users (SAFETEA-LU).

Though researchers have published numerous studies on various safety-related work zone issues, there are still numerous challenges to be addressed and practices to be improved upon. Safety in work zones on two-lane rural highways is one such challenge and the focus of this study. A driver's safe driving practices are a big factor in the safety of other motorists and construction workers. Temporary traffic control (TTC) measures are used to inform drivers of upcoming road conditions. Work zone safety is also affected in large part by the type of vehicles passing through the work zone. Benekohal and Shim (1999) found that $90 \%$ of trac-

\footnotetext{
* Corresponding author. Tel.: +1 785864 2991; fax: +1 7858645631.

E-mail addresses: ybai@ku.edu (Y. Bai), finger84@ku.edu (K. Finger), ylkx7@ ku.edu (Y. Li).

${ }^{1}$ Tel.: +1 785864 2598; fax: +1 7858645631 .
}

tor-trailer truck drivers surveyed considered travelling through a work zone to be more dangerous than travelling on roads not under construction. In this study, researchers evaluated the effectiveness of TTC measures based on motorists' responses to signage by placing the motorists in one of three classes based on the length of their vehicle: passenger car, truck, and semitrailer.

\section{Literature review}

A study conducted in the United States found that average fatalities per crash and fatal crash frequency were higher in work zones than in non-work zones (AASHTO, 1987). The study found that rural highways accounted for $69 \%$ of all fatal crashes. Another study found that accident rates on highways are 7-9\% higher in work zones than on roads without any construction (Wang et al., 1996). In the State of Kansas, 63\% of the fatal crashes and one-third of all injury crashes took place in two-lane highway work zones ( $\mathrm{Li}$ and Bai, 2008a). With the increased likelihood of crashes and fatalities in work zones and the rising number of work zones across the nation, it is obvious that work zone safety must be improved. Numerous studies have been conducted on the subject of work zone safety in the United States (AASHTO, 1987; Pigman and Agent, 1990; Wang et al., 1996; Garber and Zhao, 2002; Schrock et al., 2004; Li and Bai, 2008b). These studies have focused on a broad range of topics from safety implications and risk analysis 
of highway work zones to analyzing crashes within work zones to the evaluation and development of technologies and signage in work zones. Besides the studies conducted in the United States, researchers in Europe, Japan, and China have investigated the work zone safety issue and recommended countermeasures to mitigate the vehicle crash risks (Steinke et al., 2000; Wu and Wu, 2004; Takemoto et al., 2008).

According to the Manual on Uniform Traffic Control Devices (MUTCD) a work zone is divided into four areas: the advance warning area, the transition area, the activity area, and the termination area (FHWA, 2003). Previously published studies agree that there is an unbalanced distribution of crashes within these four areas. In different literature the advanced warning area (Pigman and Agent, 1990), the activity area (Garber and Zhao, 2002; Schrock et al., 2004), the transition area, and the termination area (Nemeth and Migletz, 1978; Hargroves, 1981) were recognized as being the most dangerous area in terms of severe crash frequency. There have been plenty of studies on the development, use, and effectiveness of changeable message signs (CMS) in reducing speeds and informing traffic of the pending work zone ahead. Various studies have shown that using a CMS is more effective than traditional work zone traffic control devices at reducing the number of speeding vehicles in work zones (Garber and Patel, 1994; Garber and Srinivasan, 1998; Brewer et al., 2006). However, Richards and Dudek (1986) state that CMS could result in only modest reductions (less than $10 \mathrm{mph}$ ) when used alone and that they would lose their effectiveness if operated continuously for long periods with the same message. Other researchers have decided to concentrate their efforts on examining the actual vehicles and drivers passing through the work zone. A major work zone safety concern is the frequent involvement of heavy trucks in work zone crashes. Studies have found that the percentage of truck-involved crashes was much higher in work zones (AASHTO, 1987; Pigman and Agent, 1990). Studies also found that heavy truck-related crashes were more likely to involve multiple vehicles, and thus frequently resulted in fatalities and large monetary loss (Pigman and Agent, 1990; Schrock et al., 2004). However, a study completed in Georgia found that single-vehicle crashes, angle, and head-on collisions were the dominant type of fatal work zone crashes (Daniel et al., 2000).

Though there has been a substantial amount of research conducted and studies published on work zone safety around the world, questions remain particularly in the areas of CMS use and vehicle type causality of crashes. A vast majority of studies focus their efforts on the interstate highway system and on rural primary roads. There have been only a handful of studies which focus their efforts on rural, two-lane highways. Few of these studies have attempted to evaluate CMS or focus on vehicle size. However, study on rural two-lane work zone safety is urgently needed due to the fact that many vehicle crashes occur in these work zones around the world each year.

\section{Objectives}

The primary objective of this research project was to determine motorists' responses to temporary traffic signs in rural, two-lane highway work zones. These signs include a portable changeable message sign (PCMS) and a temporary traffic sign (TTS), specifically W20-1 ("Road Work Ahead"). The motorists' responses were measured by vehicle speed change before and after passing the signs. Findings of this research project will help traffic engineers to better design the temporary traffic control devices in rural, two-lane work zones and take necessary safety countermeasures to prevent vehicle crashes.

\section{Data collection and preliminary analysis}

\subsection{Data collection}

To achieve the research objective, field experiments were conducted in two rural, two-lane work zones on US-36 and US-73 in Kansas following a construction company as it moved from one segment to another down each road to resurface the highway. Both US-36 and US-73 had a statutory speed limit of $65 \mathrm{mph}$ and a posted work zone speed limit of $45 \mathrm{mph}$. The field experiments and data collection were conducted for 4 days (June 3-6, 2008) on US-36 and for 1 day (June 13, 2008) on US-73. Two traffic signs, a PCMS and a TTS (W20-1), were utilized and setup in three cases in the field experiments including:

1. PCMS turned off,

2. PCMS turned on ("Slow Down, Drive Safely"),

3. TTS: W20-1 ("Road Work Ahead").

Data for each case were collected at the same location on the same day. Each case was setup in the work zones in about two hours per day. After the $2 \mathrm{~h}$ period, the setup was switched to another case. In addition, the order of the treatments was varied each day to account for time-of-day biases. For example, on the first day, data of PCMS OFF were collected first, followed by PCMS ON and TTS. However, on the second day, data of PCMS ON were recorded first, followed by TTS and PCMS OFF. This pattern was utilized through the entire data collection process.

Two radar sensor systems (SmartSensor HD Model 125) were setup one in front of and another behind the PCMS or TTS to collect vehicle speed and length data. Figs. 1 and 2 provide a detailed description of the layout and spatial referencing of materials for each case. The distance between W20-1 and Flagger for cases 1 and 2 was about 800 feet, same as the distance between W20-4 and flagger for case 3. Fig. 3 shows the PCMS and the typical setup of the speed sensor system.

The authors would like to indicate that the vehicle speed changes were due to the combination of the influence of the traffic signs and drivers' awareness of work zone conditions. In this research project, traffic signs include the PCMS, the W20-1 (Road Work Ahead), and the W20-4 (One Lane Road Ahead). For case 3 as shown in Fig. 2, because the W20-4 was placed in 200 feet apart from the W20-1 which was within the typical distance of many motorists, therefore, these two signs should be considered as one configuration in the TTS case. Both of them might have impact on drivers' behavior. In this research project, authors did not directly measure the impact of the W20-4 sign due to the resource limitation. The impact of the W20-4 sign on drivers' behavior is a research topic that should be investigated in the future.

\subsection{Preliminary data analysis}

The raw data collected from the field experiments went through an extensive screening and analysis process. The raw data was first thoroughly screened by matching individual vehicle data points recorded on both sensors 1 and 2. Any vehicle that was recorded on one sensor but did not have a corresponding data point on the other sensor was discarded. Also, if both sensors had two corresponding data points but one sensor did not record an accurate vehicle length, speed, or was missing any other necessary value, the data point was discarded from the data population. Finally, if either sensor recorded a vehicle speed less than $20 \mathrm{mph}$, the point was excluded from the data set because the sensor's specifications stated that the device could not properly record speeds under $20 \mathrm{mph}$. Through this initial data screening and analysis, the raw 


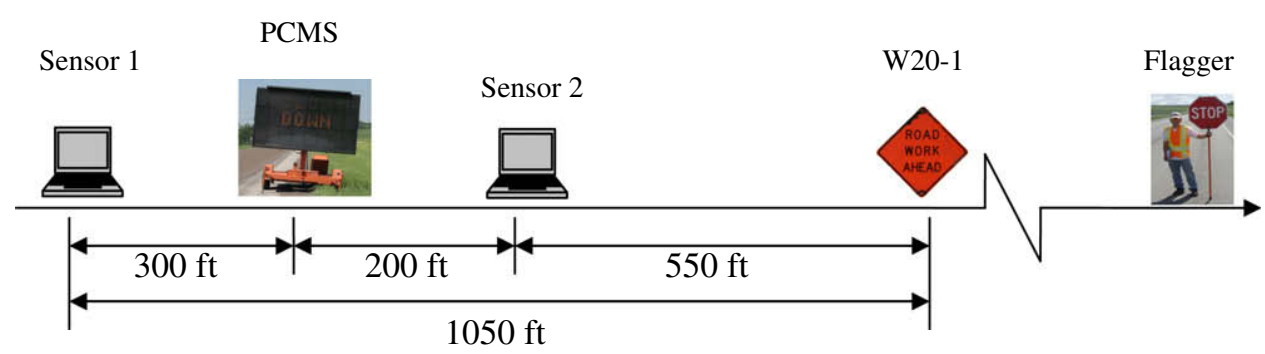

Fig. 1. Location of speed sensors and PCMS sign in work zone for cases 1 and 2.

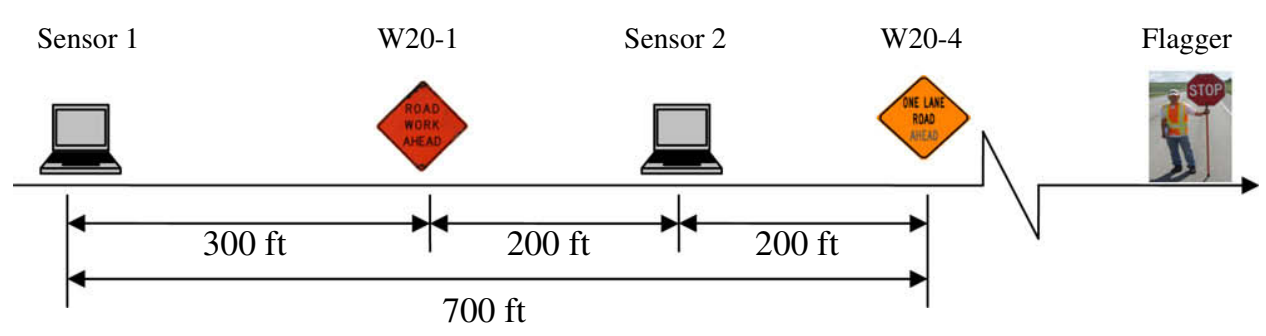

Fig. 2. Location of speed sensors and TTS (W20-1) in work zone for case 3.

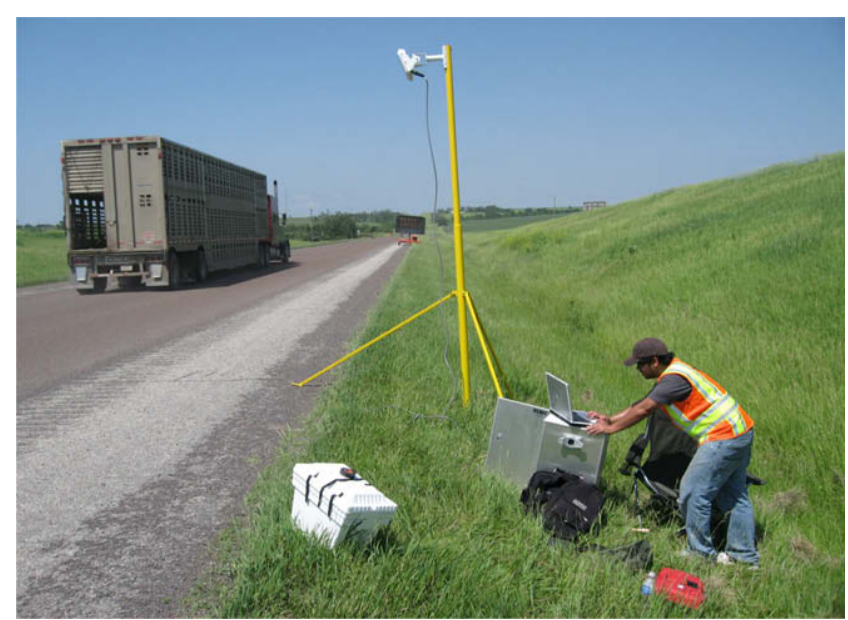

Fig. 3. PCMS and setup of the speed sensor system.

data was narrowed down and sorted before using a statistical program to perform further analyses.

The values of speed and length for each vehicle collected by the two sensors were then inserted into a statistical analysis program along with a corresponding numerical value to represent which sign was present when the values were recorded. The differences in the values of speed and length between sensors 1 and 2 were then calculated and a frequency analysis was performed based on these calculated values. The results show that the values of vehicle length measured by sensors were not consistent due to the vehicle speed changes. The standard deviation of vehicle length was 3.5 feet. It was decided that the majority of values were within two standard deviations ( $7 \mathrm{feet}$ ), and therefore all other points with a positive or negative change greater than 7 feet were discarded. This was done to account for errors in the ability of the sensors to accurately read a vehicle's length. The final population consisted of 876 vehicle data points, broken down by case in Table 1 and by class in Table 2 .

The vehicle classes were determined using AASHTO Green Book definitions. A passenger car is defined as being 19 feet long and the
Table 1

Break down of data points by case.

\begin{tabular}{llc}
\hline Case & No. of data & Percent of total (\%) \\
\hline PCMS OFF & 409 & 47 \\
PCMS ON & 334 & 38 \\
TTS & 133 & 15 \\
Total & 876 & 100 \\
\hline
\end{tabular}

Table 2

Break down of data points by vehicle class.

\begin{tabular}{llc}
\hline Vehicle class & No. of data & Percent of total (\%) \\
\hline Passenger car & 394 & 45 \\
Truck & 381 & 43 \\
Semitrailer & 101 & 12 \\
Total & 876 & 100 \\
\hline
\end{tabular}

smallest semitrailer (WB-12[WB-40]) is defined as being 45.5 feet long (AASHTO, 2004). Therefore, class 1 (passenger car) includes any vehicle with an average length of 19 feet or less and class 3 (semitrailer) includes any vehicle with an average length equal to or greater than 45 feet. Class 2 (truck) is defined as any vehicle with an average length greater than 19 feet and less than 45 feet. After the individual data points were sorted by length and assigned a class, statistical analyses were performed.

\section{Frequency analysis}

The frequencies of individual vehicle speed changes, sorted by vehicle class, are shown in the histograms in Fig. 4. Vehicle speed changes were assumed to be normally distributed. This assumption is generally accurate enough for the statistical analyses when the data points are large enough under non-perfect field conditions. Table 3 shows the results of the data collected during field experiments. Researchers break the data down by vehicle class and then display the results for each case based on the vehicle class.

When the PCMS was turned off, the passenger car, truck, and semitrailer classes experienced speed reductions of $2.4 \mathrm{mph}$, 


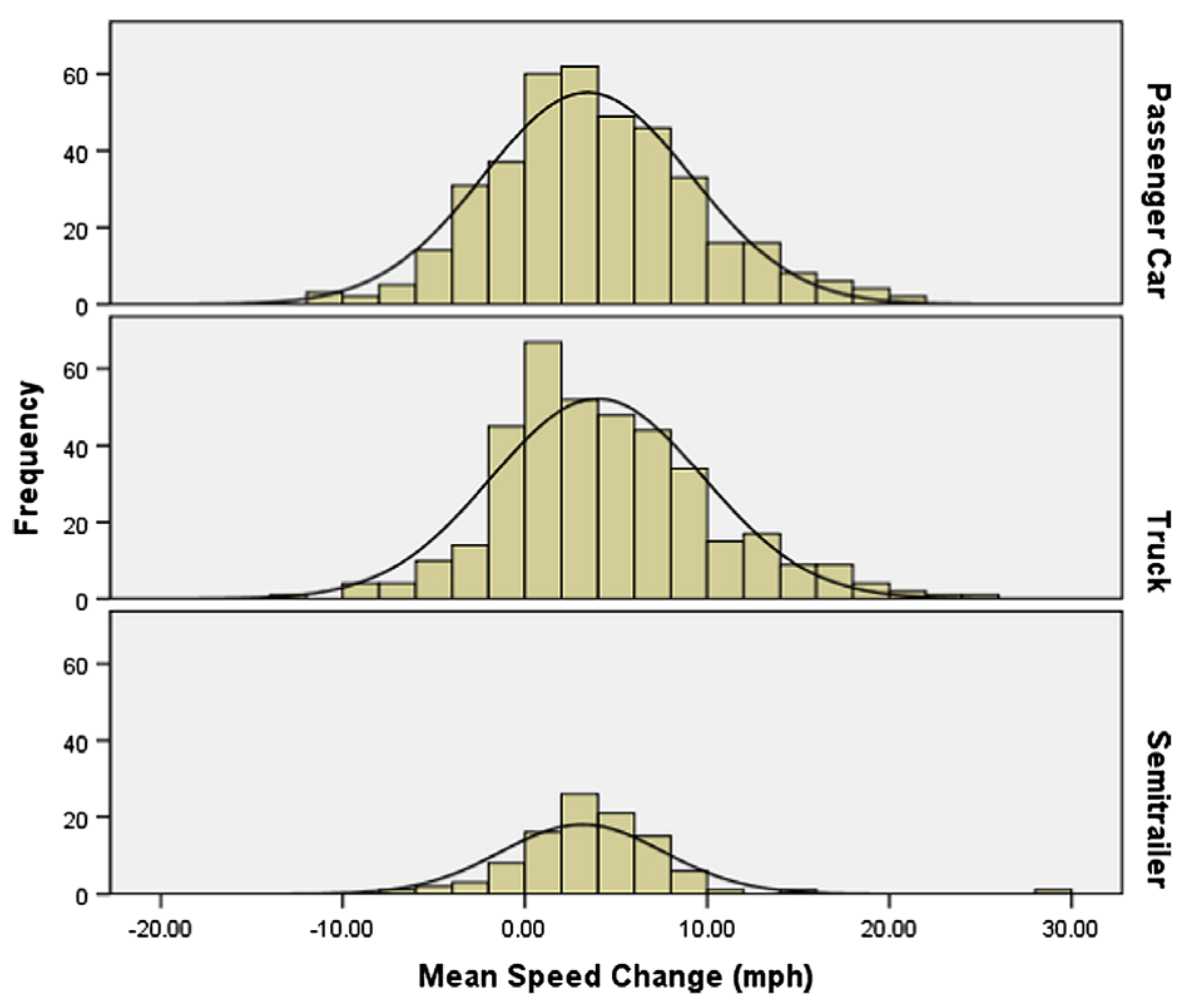

Fig. 4. Histograms showing frequency of speed change by vehicle class.

Table 3

Mean speed values based on class for each case.

\begin{tabular}{|c|c|c|c|c|c|c|}
\hline Vehicle class & Case & No. & Sensor 1 speed (mph) & Sensor 2 speed (mph) & Mean speed change (mph) & Speed change percentage (\%) \\
\hline \multirow[t]{3}{*}{ Passenger car } & PCMS OFF & 188 & 60.2 & 57.9 & 2.4 & 3.9 \\
\hline & PCMS ON & 132 & 58.5 & 54.5 & 3.9 & 6.7 \\
\hline & TTS & 74 & 50.5 & 45.3 & 5.2 & 10.3 \\
\hline \multirow[t]{3}{*}{ Truck } & PCMS OFF & 174 & 59.4 & 55.7 & 3.7 & 6.2 \\
\hline & PCMS ON & 154 & 57.0 & 52.3 & 4.7 & 8.3 \\
\hline & TTS & 53 & 48.2 & 45.4 & 2.8 & 5.8 \\
\hline \multirow[t]{3}{*}{ Semitrailer } & PCMS OFF & 47 & 61.6 & 58.6 & 3.0 & 4.8 \\
\hline & PCMS ON & 48 & 59.1 & 56.1 & 3.1 & 5.2 \\
\hline & TTS & 6 & 49.2 & 44.2 & 5.0 & 10.2 \\
\hline
\end{tabular}

$3.7 \mathrm{mph}$, and $3.0 \mathrm{mph}$ over a 500 foot distance, respectively. These speed reductions showed that the PCMS, though turned off, could still affect a vehicle's speed. The inactive PCMS produced the highest speed reduction of $3.7 \mathrm{mph}$, or a $6.2 \%$ reduction, in the truck class over a 500 foot distance.

When the PCMS was turned on, the passenger car, truck, and semitrailer classes experienced speed reductions of $3.9 \mathrm{mph}$, $4.7 \mathrm{mph}$, and $3.1 \mathrm{mph}$ over a 500 foot distance. These speed reductions demonstrated that when the PCMS was on, the speed reductions of the passenger car and truck classes increased by $1.5 \mathrm{mph}$ and $1.0 \mathrm{mph}$ over a 500 foot distance, respectively. If measured in percentage, the use of a PCMS caused the greatest speed reduction in the truck class, up to $8.3 \%$.

When a TTS (no PCMS) was present on the highway, the passenger car, truck, and semitrailer classes experienced speed reductions of $5.2 \mathrm{mph}, 2.8 \mathrm{mph}$, and $5.0 \mathrm{mph}$ over a 500 foot distance, respectively. These speed reductions showed that of the vehicles approaching the advance warning area, the passenger car class slowed down the most.

As seen in Table 3 above, the greatest speed reduction for the passenger car class occurred when approaching the TTS in the ad- vance warning area with a $10.3 \%$ reduction. The greatest speed reduction for the truck class occurred when the PCMS was on, with an $8.3 \%$ reduction. The semitrailer class experienced the greatest speed reduction of $10.2 \%$ when approaching the advance warning area with a TTS.

For two of the three conditions, the average speed of the semitrailer class was greater than the other two classes. This indicates that the semitrailer drivers usually maintain their high speeds when on rural highways. The PCMS was not effective in reducing semitrailer vehicle speeds in rural highway work zones. Based on the analysis results, the PCMS, when either on or off, had a greater effect on the truck class than the TTS $(8.3 \%$ vs. $5.8 \%$ or $6.2 \%$ vs. $5.8 \%)$. The change in speed for different vehicle classes is shown in Fig. 5.

Fig. 5 provides a visual of the breakdown of mean speed changes for each case based on vehicle class. The bar chart in Fig. 5 indicates that the truck class was the most responsive vehicle class to cases 1 and 2, both involving the PCMS in rural work zones. The chart also indicates that the truck class was the least responsive vehicle class to case 3, involving the TTS in rural work zones. Another correlation that can be drawn from the chart is that the 


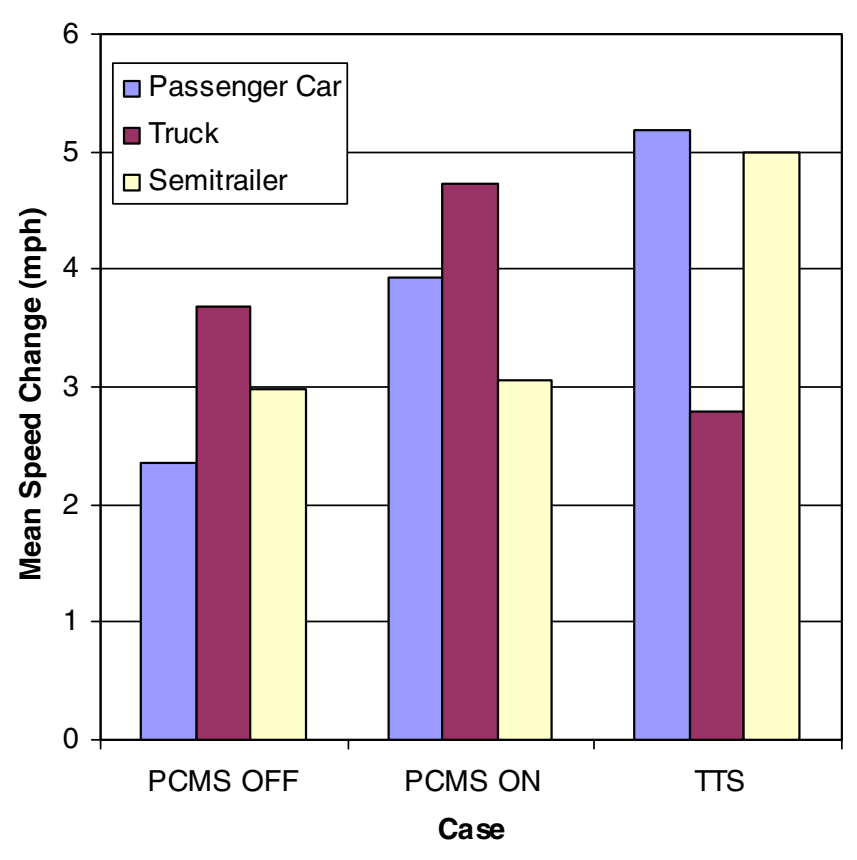

Fig. 5. Mean speed change of vehicle classes for three cases.

passenger car and semitrailer classes were more responsive to warning messages than to the inactive PCMS on the roadside in rural work zones.

\section{Significance of test analysis}

Hypothesis tests were also conducted during the data analysis process. The null hypothesis of this research was that there was no change between cases in the mean speeds of the three vehicle classes. The alternative hypothesis was that there was a difference between cases in the mean speed of one or more of the vehicle classes. A univariate analysis of variance (UNIANOVA) was performed on the data to determine whether or not the interaction between the three cases and the three vehicle classes was significant. UNIANOVA is a two-way analysis of variance with vehicle class and case as the two factors. The results of the UNIANOVA test are shown in Table 4. For the null hypothesis to be rejected and for there to be a significant interaction between the two effects (vehicle class and case) the value of significance must be less than 0.05 (for a $95 \%$ confidence level). Table 4 shows that testing vehicle class and case separately, none of them is significant. Testing the interaction of vehicle class by case, the result is significant. Since the test returned a significance value of 0.019 for the interaction of vehicle class and case, the null hypothesis was rejected in favor of the alternative hypothesis.

Further UNIANOVA tests were performed to determine which factors were causing the significance in the interaction between vehicle class and case. Table 5 shows a comparison of each individual vehicle class with the cases. It indicates that the significance is between one or more of the three sign cases and the passenger car and truck classes only, with significance values of 0.000 and 0.060 , respectively.

Table 6 shows a more in-depth pairwise comparison of both the passenger car and truck classes with the three cases. This analysis was performed by taking the data from the specified vehicle class and comparing the mean speed change between only two of the cases at a time to determine significance. The results in Table 6 indicate that for the passenger car class there was a significant in the difference between the PCMS OFF case and both the PCMS ON and TTS cases, but no significance in the difference between the PCMS ON and TTS cases. Table 6 also indicates that for the truck class there was a significant difference between the PCMS ON case and TTS case, but no significance in the difference between the PCMS OFF case and the PCMS ON and TTS cases. The most important thing to note about the results in Table 6 is that the PCMS ON case caused a significantly greater mean speed change than the TTS case. This is important because $43 \%$ of vehicles measured during this research were in the truck class.

Table 4

UNIANOVA test of between-subjects effects.

\begin{tabular}{|c|c|c|c|c|c|}
\hline Source & Type III sum of squares & Degrees of freedom & Mean square & $F$ & Significance \\
\hline Corrected model & $764.395^{\mathrm{a}}$ & 8 & 95.549 & 3.072 & .002 \\
\hline Intercept & 4264.488 & 1 & 4264.488 & 137.097 & .000 \\
\hline Vehicle class & 1.713 & 2 & .856 & .028 & .973 \\
\hline Case & 142.241 & 2 & 71.121 & 2.286 & .102 \\
\hline Interaction (vehicle class by case) & 367.435 & 4 & 91.859 & 2.953 & .019 \\
\hline Error & 26968.540 & 867 & 31.106 & & \\
\hline Total & 39255.000 & 876 & & & \\
\hline Corrected total & 27732.935 & 875 & & & \\
\hline
\end{tabular}

Note : Dependent variable $=$ mean speed change.

${ }^{\text {a }} R$ squared $=.028$ (adjusted $R$ squared $=.019$ ).

Table 5

Comparison of individual vehicle classes with cases.

\begin{tabular}{|c|c|c|c|c|c|c|}
\hline Vehicle class & Analysis type & Sum of squares & Degrees of freedom & Mean square & $F$ & Significance \\
\hline \multirow[t]{2}{*}{ Passenger car } & Contrast & 478.505 & 2 & 239.252 & 7.692 & 0.000 \\
\hline & Error & 26968.54 & 867 & 31.106 & & \\
\hline \multirow[t]{2}{*}{ Truck } & Contrast & 175.1 & 2 & 87.55 & 2.815 & 0.060 \\
\hline & Error & 26968.54 & 867 & 31.106 & & \\
\hline \multirow[t]{2}{*}{ Semitrailer } & Contrast & 22.268 & 2 & 11.134 & 0.358 & 0.699 \\
\hline & Error & 26968.54 & 867 & 31.106 & & \\
\hline
\end{tabular}

Note: Each $F$ tests the simple effects of sign case within each level combination of the other effects shown. These tests are based on the linearly independent pairwise comparisons among the estimated marginal means. 
Table 6

Pairwise comparison of class by case.

\begin{tabular}{|c|c|c|c|c|c|c|c|}
\hline \multirow[t]{2}{*}{ Vehicle class } & \multirow[t]{2}{*}{ (I) Case } & \multirow[t]{2}{*}{ (J) Case } & \multirow[t]{2}{*}{ Mean difference $(I-J)$} & \multirow[t]{2}{*}{ Std. error } & \multirow[t]{2}{*}{ Significance $^{a}$} & \multicolumn{2}{|c|}{$95 \%$ Confidence interval for difference ${ }^{a}$} \\
\hline & & & & & & Lower bound & Upper bound \\
\hline \multirow[t]{3}{*}{ Passenger car } & PCMS OFF & PCMS ON & $-1.588^{*}$ & 0.636 & 0.013 & -2.839 & -0.338 \\
\hline & PCMS OFF & TTS & $-2.825^{*}$ & 0.769 & 0.000 & -4.336 & -1.313 \\
\hline & PCMS ON & TTS & -1.236 & 0.813 & 0.129 & -2.836 & 0.363 \\
\hline \multirow[t]{3}{*}{ Truck } & PCMS OFF & PCMS ON & -1.043 & 0.642 & 0.105 & -2.305 & 0.219 \\
\hline & PCMS OFF & TTS & 0.886 & 0.910 & 0.331 & -0.904 & 2.675 \\
\hline & PCMS ON & TTS & $1.928^{*}$ & 0.924 & 0.038 & 0.112 & 3.745 \\
\hline
\end{tabular}

The mean difference is significant at the .05 level.

a Adjustment for multiple comparisons: least significant difference (equivalent to no adjustments).

\section{Conclusions}

Preservation, rehabilitation, and expansion of rural, two-lane highways require the setup of a large number of work zones. To improve safety in work zones, many types of signage have been developed and employed. However, the effectiveness of some signs has not been quantified. Researchers of this project determined motorists' responses to signage (PCMS and TTS) in rural, two-lane highway work zones using field experiments. The message displaced on the PCMS was Slow Down, Drive Safely. The data analysis results show that the PCMS was effective in reducing vehicle speeds in two-lane work zones. When the PCMS was turned on the device reduced passenger car vehicle speeds by $3.9 \mathrm{mph}$, truck vehicle speeds by $4.7 \mathrm{mph}$, and semitrailer vehicle speeds by $3.1 \mathrm{mph}$ over a 500 foot distance. When the PCMS was turned off, passenger car vehicle speeds were reduced by $2.4 \mathrm{mph}$, truck vehicle speeds by $3.7 \mathrm{mph}$, and semitrailer vehicle speeds by $3.0 \mathrm{mph}$ over a 500 foot distance. When a TTS (no PCMS) was on the road and the vehicles approached the advance warning area, passenger car speeds dropped by $5.2 \mathrm{mph}$, truck speeds by $2.8 \mathrm{mph}$, and semitrailer speeds by $5.0 \mathrm{mph}$ over a 500 foot distance. The TTS (W20-1) had more effect on passenger car and semitrailer speeds than the PCMS ON at reducing these types of vehicle speeds. Also, based on the results of the UNIANOVA tests and the pairwise comparison, researchers concluded that the mean speed reduction of truck vehicles caused by PCMS ON was significantly greater than TTS and PCMS OFF. This is important because $43 \%$ of vehicles measured during this study were in the truck vehicle class. A reduction in vehicular speed allows for greater reaction time to avoid crashes and potentially creates a safer environment for drivers and workers in the work zones. Thus, the authors recommend that both the PCMS and the TTS (W20-1) should be utilized in the work zones. Currently, the PCMS is an optional sign in the work zones. As indicated in this study, deploying PCMS will reduce the mean speed of truck vehicles approaching the work zones.

The authors would like to indicate that the vehicle speed changes were due to the combination of the influence of the traffic signs and drivers' awareness of work zone conditions. In this research project, traffic signs include the PCMS, the W20-1 (Road Work Ahead), and the W20-4 (One Lane Road Ahead). Because the W20-4 was placed right after the W20-1 within the typical distance of many motorists, therefore, these two signs should be considered as one configuration in the TTS case. Both of them might have impact on drivers' behavior. In this research project, authors did not directly measure the impact of the W20-4 sign due to the resource limitation. The impact of the W20-4 sign on drivers' behavior is a research topic that should be investigated in the future. In addition, the drivers' awareness of work zone conditions was difficult to measure using the existing technologies. In this project, authors only measured the influence of the traffic signs with the understanding that drivers' awareness of work zone conditions may also have impact on the speed changes. Additional re- search is needed to quantity the impact of drivers' awareness of work zone conditions on the vehicle speed changes. Furthermore, existing knowledge cannot explain exactly what reasons caused the effects on speed reduction differ between passenger cars and semitrailers under TTS configuration (W20-1 and W20-4) and trucks under PCMS ON condition. Further research is needed to unlock the secret.

\section{Acknowledgments}

The authors would like to express their gratitude and thanks to Mr. Kevin F. Palic, P.E., Construction Engineer; Mr. Luke Perry, Senior Engineering Technician; and Mr. Pat Haverkamp, Senior Engineering Technician from the Kansas Department of Transportation (KDOT) for their valuable help during the course of this study. The authors would also like to thank Mr. Mickey Waxman, Statistic Consultant, for his advice and help in statistical analysis. Special thanks also go to the University of Kansas Transportation Research Institute, KDOT, and the Federal Highway Administration for providing generous financial support.

\section{References}

AASHTO, 1987. Summary Report on Work Zone Crashes. Standing Committee on Highway Traffic Safety. American Association of State Highway and Transportation Officials, Washington, DC.

AASHTO, 2004. AASHTO Green Book: A Policy on Geometric Design of Highways and Streets, fifth ed. American Association of State Highway and Transportation Officials, Washington, DC.

Benekohal, R.F., Shim, E., 1999. Multivariate analysis of truck drivers' assessment of work zone safety. Journal of Transportation Engineering 125 (5), 398-406.

Brewer, M.A., Pesti, G., Schneider IV, W., 2006. Improving compliance with work zone speed limits: effectiveness of selected devices. Journal of the Transportation Research Record (1948), 67-76.

Daniel, J., Dixon, K., Jared, D., 2000. Analysis of fatal crashes in Georgia work zones. Journal of the Transportation Research Record (1715), 18-23.

FHWA, 2003. Manual on Uniform Traffic Control Devices for Streets and Highways. Federal Highway Administration, Washington, DC.

Garber, N.J., Patel, S.T., 1994. Effectiveness of Changeable Message Signs in Controlling Vehicles Speeds in Work Zones. Report No. VTRC 95-R4. Virginia Transportation Research Council, Charlottesville, Virginia.

Garber, N.J., Srinivasan, S., 1998. Effectiveness of Changeable Message Signs in Work Zones: Phase II. Report No. VTRC 98-R10. Virginia Transportation Research Council, Charlottesville, Virginia.

Garber, N.J., Zhao, M., 2002. Crash Characteristics at Work Zones. Report No. VTRC 02-R12. Virginia Transportation Research Council, Charlottesville, Virginia.

Hargroves, B.T., 1981. Vehicle crashes in highway work zones. Journal of Transportation Engineering 107 (TE5), 525-539.

Li, Y., Bai, Y., 2008a. Comparison of characteristics between fatal and injury accidents in the highway construction zones. Safety Science, Elsevier 46 (4), 646-660.

Li, Y., Bai, Y., 2008b. Development of crash-severity-index models for the measurement of work zone risk levels. Accident Analysis and Prevention, Elsevier 40 (5), 1724-1731.

Nemeth, Z.A., Migletz, D.J., 1978. Accident characteristics before, during, and after safety upgrading projects on Ohio's rural interstate system. Journal of the Transportation Research Record (672), 19-23.

Pigman, J.G., Agent, K.R., 1990. Highway crashes in construction and maintenance work zones. Journal of the Transportation Research Record (1270), 12-21.

Richards, S.H., Dudek, C.L., 1986. Implementation of work zone speed control measures. Journal of the Transportation Research Record (1086), 36-42. 
Schrock, D.S., Ullman, G.L., Cothron, A.S., Kraus, E., Voigt, A.P., 2004. An Analysis of Fatal Work Zone Crashes in Texas. Report FHWA/TX-05/0-4028-1, FHWA. US Department of Transportation.

Steinke, D.P., Sanderson, L., Byrnes, J.F., Conrad, J., Forrestel, R., Harrington-Hughes, K., Kobetsky, K.F., Lanford, S., Snyder-Petty, K., Testa, D., Wilkerson, J.D., 2000. Methods and Procedures to Reduce Motorist Delays in European Work Zones. Final Report No. FHWA-PL-00-001. Federal Highway Administration, Washington, DC 20590

Takemoto, A., Hirasawa, M., and Asano, M., 2008. Improving the nighttime visibility of signs and workers in road work zones in Japan. In: Proceedings of the 87th
TRB Annual Meeting. Transportation Research Board, Washington, DC, January 13-17 (in CD-ROM).

Wang, J., Hughes, W.E., Council, F.M., Paniati, J.E., 1996. Investigation of highway work zone crashes: what we know and what we don't know. Journal of the Transportation Research Record (1529), 54-64.

Wu, Xinkai, Wu, Bing, 2004. Discussion on speed control measures in highway maintenance and construction work zone. Highway (7), 132-137 (published in Chinese). 